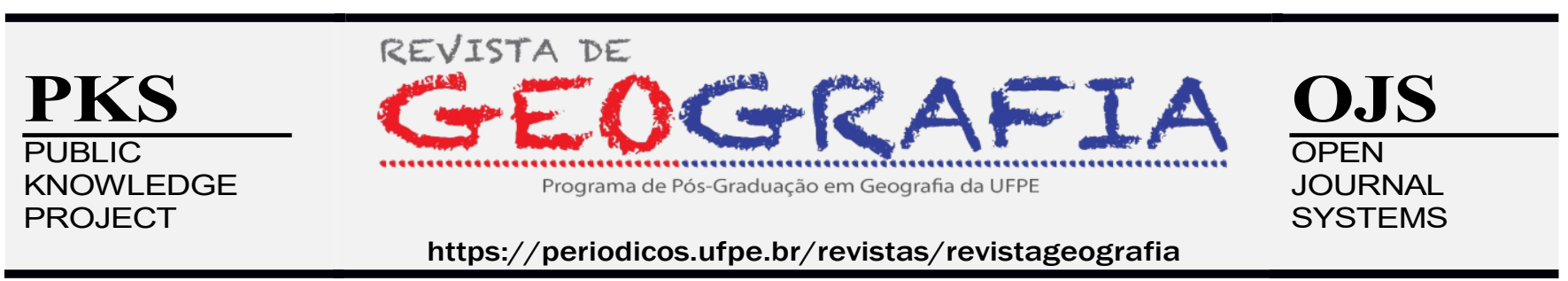

\title{
AVALIAÇÃO ESPAÇO-TEMPORAL DO SALDO DE RADIAÇÃO PARA ÁREA HETEROGÊNEA EM REGIÃO SEMIÁRIDA
}

\author{
Hélio Nogueira Bezerra ${ }^{1}$, Joel Medeiros Bezerra ${ }^{2}$, José Espínola Sobrinho ${ }^{3}$, Wagner Bandeira Silva ${ }^{4}$, \\ Alana Ticiane Alves Rêgo ${ }^{5}$
}

\begin{abstract}
${ }^{1}$ Mestre em Engenharia Sanitária pela Universidade Federal do Rio Grande do Norte (UFRN), Servidor no Instituto Federal de Educação, Ciência e Tecnologia do Rio Grande do Norte (IFRN), Campus Mossoró. E-mail: helionogueirab@gmail.com; http://orcid.org/0000-0001-5939-2043

${ }^{2}$ Professor Adjunto da Universidade Federal Rural do Semi-Árido (UFERSA), Departamento de Engenharias e Tecnologia, Campus Paudos Ferros. E-mail: joel.medeiros@ufersa.edu.br; http://orcid.org/0000-0002-8150-4125

3 Professor titular da UFERSA, Departamento de Engenharias e Ciências Ambientais, Campus Mossoró. E-mail: jespinola@ufersa.edu.br; http://orcid.org/0000-0002-4953-245X

${ }^{4}$ Engenheiro Ambiental e Sanitarista pela UFERSA, Campus Pau dos Ferros. E-mail: wagnerbandeira2010@hotmail.com; http://orcid.org/0000-0003-0415-5459

${ }^{5}$ Engenheira Ambiental e Sanitarista pela UFERSA, Campus Pau dos Ferros, Mestranda em Ciências Naturais pela Universidade do Estado do Rio Grande do Norte (UERN).E-mail:alana_ticiane10@hotmail.com; http://orcid.org/0000-00019005-2610
\end{abstract}

Artigo recebido em 27/03/2020 e aceito em 13/08/2021

\section{RESUMO}

O presente estudo tem como objetivo avaliar a evolução espaço-temporal do saldo de radiação (Rn) instantâneo e diário em área de uso e ocupação heterogênea, com predominância de cobertura vegetal de Caatinga, região semiárida, a partir de produtos de sensoriamento remoto associados a dados meteorológicos. A área de estudo compreende o entorno do reservatório Dourado, situado no município de Currais Novos, que se encontra no Seridó Potiguar, mesorregião Central do estado do Rio Grande do Norte. A fim de obter a dinâmica espaço-temporal, o cálculo do Rn foi realizado para cinco imagens do Landsat 5-TM, 215/64, abrangendo os anos de 2005, 2007, 2008, 2009 e 2010. Os maiores valores de Rn instantâneo e diário foram observados para a área da lâmina d'água do reservatório Dourado, já os menores valores ocorreram em solo exposto. Já o saldo de radiação diário verificou-se uma baixa variação em escala temporal. A variação sazonal apresentou-se coerente com o esperado, diante dos dados de superfície coletados em estação meteorológica. O Rn instantâneo e o Rn24h sofreram influência da precipitação em sua variação sazonal em regiões semiáridas, provocada pela disponibilidade de água no solo e pelo desenvolvimento da vegetação de Caatinga.

Palavras-chave: Sensoriamento remoto; Agrometeorologia; Manejo da água; Semiárido. 


\title{
SPATIO-TEMPORAL ASSESSMENT OF THE RADIATION BALANCE FOR THE HETEROGENEOUS AREA IN THE SEMI-ARID
}

\begin{abstract}
The present study aims to evaluate the spatial-temporal evolution of the instantaneous and daily radiation balance $(\mathrm{Rn})$ in a heterogeneous area of use and occupation, with predominance of vegetation cover of Caatinga, semi-arid region, from remote sensing products associated to Meteorological data. The study area comprises the surroundings of the Dourado reservoir, located in the municipality of Currais Novos, located in Seridó Potiguar, Central mesoregion of the state of Rio Grande do Norte. In order to obtain spatiotemporal dynamics, the Rn calculation was performed for five images of Landsat 5-TM, 215/64, covering the years of 2005, 2007, 2008, 2009 and 2010. The highest values of instantaneous and daily Rn were observed for the area of the water table of the Dourado reservoir, since the lowest values occurred in exposed soil. On the other hand, the daily radiation balance showed a low variation in time scale. The seasonal variation was consistent with the expected, in view of the surface data collected in meteorological station. The instantaneous $\mathrm{Rn}$ and the $\mathrm{Rn} 24 \mathrm{~h}$ were influenced by precipitation in their seasonal variation in semi-arid regions, caused by the availability of water in the soil and the development of Caatinga vegetation.
\end{abstract}

Keywords: Remote sensing; Agrometeorology; Water management; Semi-arid.

\section{INTRODUÇÃO}

A energia proveniente do Sol é o fator mais importante no desenvolvimento dos processos físicos que influenciam as condições de tempo e clima na Terra. O saldo de radiação $(\mathrm{Rn})$, pode ser definido como o balanço de radiação entre os fluxos radiativos descendentes e ascendentes de onda curta e onda longa, que atuam chegando e saindo de uma superfície (Moreira et al., 2011; Silva et al., 2011; Sá et al., 2016).

O Rn representa a quantidade de energia disponível aos processos físicos e biológicos que ocorrem na interface superfície Terrestre e atmosfera. Estando disponível para os processos de evapotranspiração, fotossíntese e de aquecimento do ar e do solo (Fietz e Fisch, 2009).

Em regiões áridas e semiáridas o conhecimento deste tipo de informação de forma confiável é necessário para o plano de distribuição de água, já que a energia disponível à superfície para os processos de aquecimento do ar e do solo, fotossíntese e evaporação da água advém do saldo das trocas radiativas de onda curta e de onda longa. Por meio dessa variável são feitos estudos relacionados ao Balanço de Energia, os quais são fundamentais no monitoramento do clima, previsão do tempo, modelagem hidrológica e meteorologia agrícola (Silva et al., 2011).

Silva et al. (2005) relatam que o Rn é uma informação de suma importância, visto que, é a variável básica na estimativa da evapotranspiração (ET) e no cálculo do balanço hídrico, que são essenciais para a utilização racional dos recursos hídricos e do uso e ocupação do solo de forma sustentável. 
O Rn é uma variável que depende necessariamente da natureza da superfície estudada, assim varia muito de acordo com o albedo, da radiação solar global e das condições de temperatura da superfície local, emissividade, nebulosidade e umidade do ar, desta forma as medições de Rn tornam-se cada vez mais frequentes (Silva et al., 2011). Tais medições são representativas de condições específicas de cada cultura, e quando há interesse na sua determinação em áreas heterogêneas, pode-se recorrer ao sensoriamento remoto (Moreira et al., 2011; Silva et al., 2011).

Nos últimos anos o Sensoriamento Remoto (SR) tem assumido grande importância no monitoramento de diversos fenômenos meteorológicos e ambientais oferecendo suporte nas previsões de tempo e melhor entendimento das mudanças climáticas, além de auxiliar no planejamento agroecológico (Bezerra et al., 2014).

Uma de suas maiores vantagens é permitir a determinação de forma direta de parâmetros biofísicos e componentes do balanço de radiação, necessitando de poucos dados de superfície (Teixeira et al., 2009).

As técnicas de SR e geoprocessamento propiciam maior frequência de atualização dos dados temporais e espaciais, agilidade no processamento destes, boa acurácia, além de serem economicamente viáveis (Allen et al., 2011), o que a torna uma poderosa ferramenta para obtenção de informações sobre manejo de recursos naturais, tais como água, solo e vegetação (Braga et al., 2009).

Dentro dessas técnicas, o Surface Energy Balance Algorithm for Land (SEBAL) vem mostrando bastante eficiência na estimativa do Rn a partir de seus modelos. Para comprovar essa hipótese no semiárido, Teixeira et al. (2011), aplicaram o SEBAL em áreas irrigadas de videira, Petrolina/PE, e concluíram que os modelos baseados em parâmetros obtidos por SR e agrometeorológicos permitem boa determinação dos componentes do balanço de radiação à superfície.

Já Silva et al. (2015), fizeram uso do modelo SEBAL para o cômputo do balanço de radiação por SR de diferentes usos de solo no sudoeste da Amazônia brasileira, avaliando a distribuição espacial e temporal, no período de 2009 a 2011. O Rn, foi maior na floresta natural, seguido pela floresta manejada, sistema silvipastoril e pastagem. Isso indica que o desmatamento da Floresta Amazônica tem a capacidade de alterar a capacidade da superfície em reter energia para os processos de evapotranspiração e para o aquecimento do ar e do solo. Como consequência, pode modificar o clima de toda a região.

Souza et al. (2016), realizaram estudo determinando o balanço de radiação em ecossistema de Caatinga preservada durante um ano de seca no semiárido Pernambucano, durante 2012 em Petrolina. Utilizando de um saldo radiômetro, afim de averiguar a interação entre a vegetação e a radiação por meio de sensores para o monitoramento da radiação. Observaram que a magnitude dos valores dos componentes do balanço de radiação foi afetada principalmente em decorrência da nebulosidade e mudanças na vegetação que afetaram principalmente os níveis de emitância e reflexão da superfície. 
Para a Caatinga, estudos desta natureza são bastante escassos, podendo-se citar os trabalhos desenvolvidos por Teixeira et al. (2008) e Bezerra (2013). Informações deste tipo são de extrema relevância para a formulação de políticas ambientais e climáticas (Baldocchi et al., 1996), reforçando a importância de sua aplicação nesse bioma.

Nesse contexto, o presente trabalho tem como objetivo avaliar a evolução espaço-temporal do saldo de radiação instantâneo e diário em área de uso e ocupação heterogênea, com predominância de cobertura vegetal de Caatinga, região semiárida, a partir de produtos de sensoriamento remoto associados a dados meteorológicos.

\section{MATERIAIS E MÉTODOS}

\section{ÁREA DE ESTUDO}

Compreende a região de entorno do reservatório Dourado, situado no município de Currais Novos, que se encontra no Seridó Potiguar, mesorregião Central do estado do Rio Grande do Norte. A área de interesse do estudo é bastante heterogênea, composta por diversos lotes de terra, utilizados principalmente para a agricultura de subsistência, com cultivos de acerola, hortaliças, leguminosas e capim elefante, além de vegetação nativa de caatinga.

O cultivo de sequeiro e de espécies de ciclo curto na região é o responsável pela instabilidade no uso e a ocupação do solo, em consequência das alterações climáticas e da disponibilidade hídrica. A Figura 1 destaca a área de estudo, que também possui áreas de vegetação nativa e de solo exposto. 
Figura 1: Mapa de Currais Novos/RN com indicação da área de estudo.

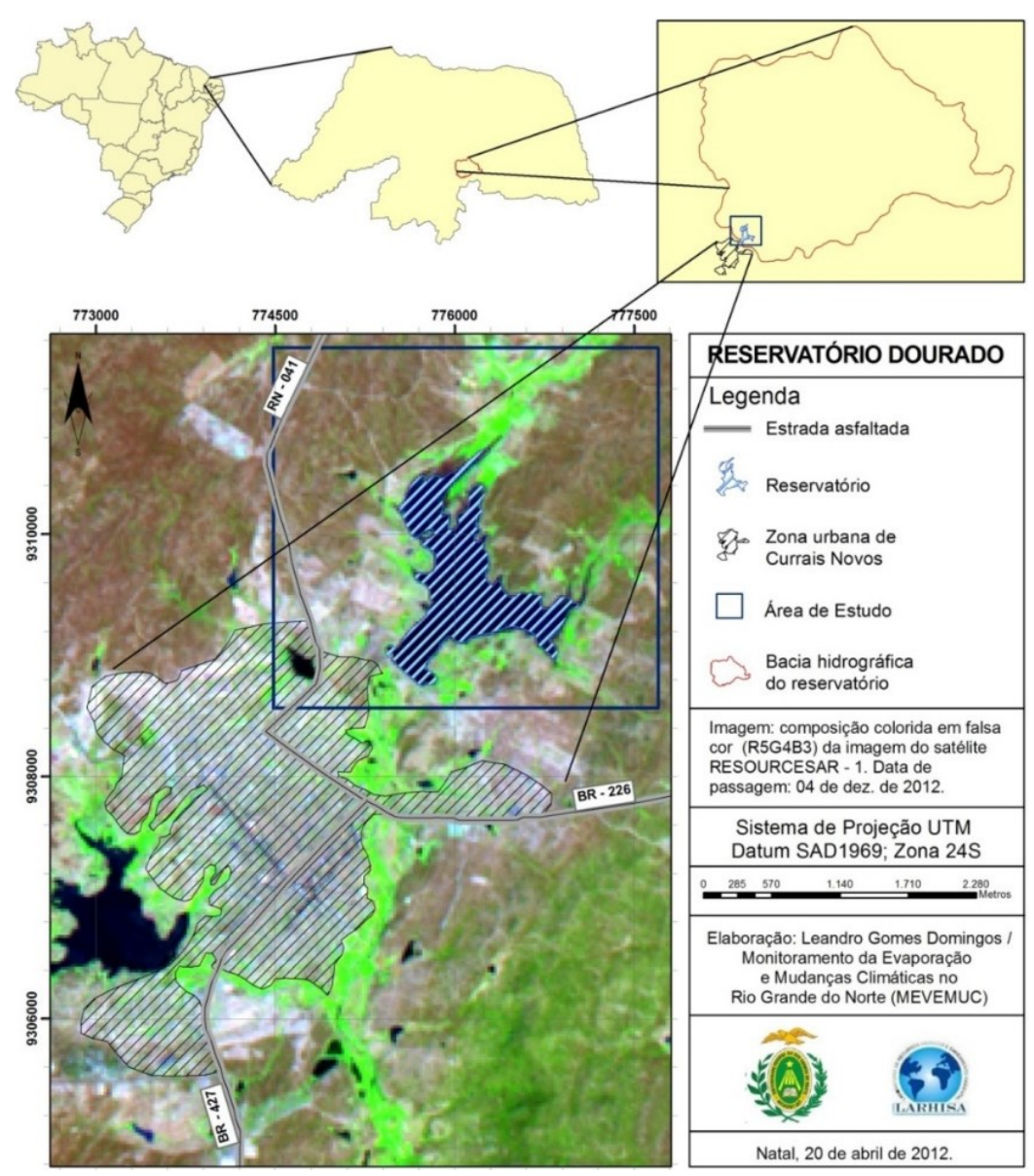

Fonte: Autores (2012).

A região possui um clima descrito pela classificação de Köppen (1928) como do tipo BSw'h' (Estepe), caracterizado por um regime de escassez e desigual distribuição de chuvas, com média pluviométrica de $470 \mathrm{~mm} /$ ano e período chuvoso compreendido entre os meses de fevereiro e junho. Essas chuvas, segundo Bezerra Júnior e Silva (2007), geram um excedente inferior a $40 \mathrm{~mm}$ de água durante o ano inteiro, e abrange 57\% do Estado, percorrendo o interior até o litoral setentrional. A área possui clima muito quente e semiárido, com insolação média anual de 2400 horas, umidade relativa média anual de $64 \%$ e temperatura média de $27,5^{\circ} \mathrm{C}$, com mínima de $18^{\circ} \mathrm{C}$ e máxima de $33^{\circ} \mathrm{C}$ (Rio Grande do Norte, 2008).

\section{DADOS METEOROLÓGICOS E ORBITAIS}

Os valores das variáveis temperatura média do ar, precipitação e insolação foram observados para o período de 01 de janeiro de 2005 a 31 de dezembro de 2010, assim como uma série histórica de precipitação para compreender melhor a variabilidade das chuvas na região. Os dados foram fornecidos pela Empresa de Pesquisa Agropecuária do Rio Grande do Norte (EMPARN), disponibilizando as medições pluviométricas de campo realizadas no município de Cruzeta/RN, que se situa a cerca de $40 \mathrm{~km}$ da área de 
estudo, sendo a estação mais próxima da área em apreço. A Figura 2 apresenta o regime pluviométrico durante o período de estudo, indicando a sazonalidade climática da área.

Figura 2: Variação da precipitação diária acumulada e da temperatura média do ar durante o período de estudo e identificação do período das imagens selecionadas para aplicação do SEBAL.

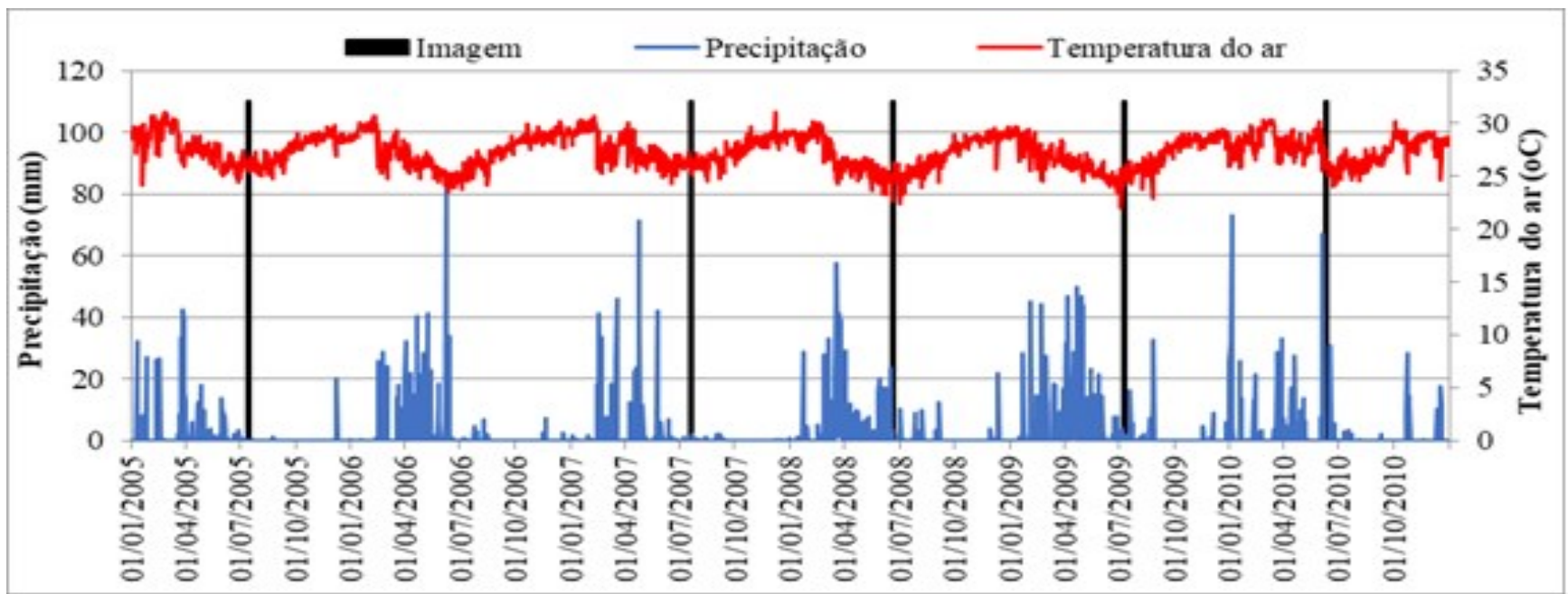

Fonte: Dados da Estação Meteorológica de Cruzeta/RN obtidos através da EMPARN (2012).

Como a estação meteorológica, de onde foram registrados os dados, não dispõe de radiômetros, apenas de heliógrafo, foram disponibilizados apenas os valores de insolação, que foram convertidos para radiação solar global, em W/m², através da Equação 1, proposta por Angströn (1924):

$$
R_{G}=R_{0} \cdot\left[a+b \cdot \frac{n}{N}\right]
$$

Sendo: $\mathrm{R}_{\mathrm{G}}$ é a radiação solar global $\left(\mathrm{W} / \mathrm{m}^{2}\right) ; \mathrm{R}_{0}$ é a radiação no topo da atmosfera $\left(\mathrm{W} / \mathrm{m}^{2}\right)$; “a” é o coeficiente linear da reta de regressão (obtido através da fórmula $\alpha=0,29 . \cos$ (Latitude) ); "b" é o coeficiente angular da reta de regressão $(0,52)$; “n” é a insolação real medida em campo (horas); e "N" é a duração máxima do brilho solar determinada para o local.

Os valores da radiação solar no topo da atmosfera e da duração máxima do brilho solar foram obtidos de Villela e Mattos (1975). A variação dos valores medidos e calculados da insolação e da radiação solar global, respectivamente, estão expostos na Figura 3. 
Figura 3: Variação da insolação e da radiação solar global durante o período de estudo.

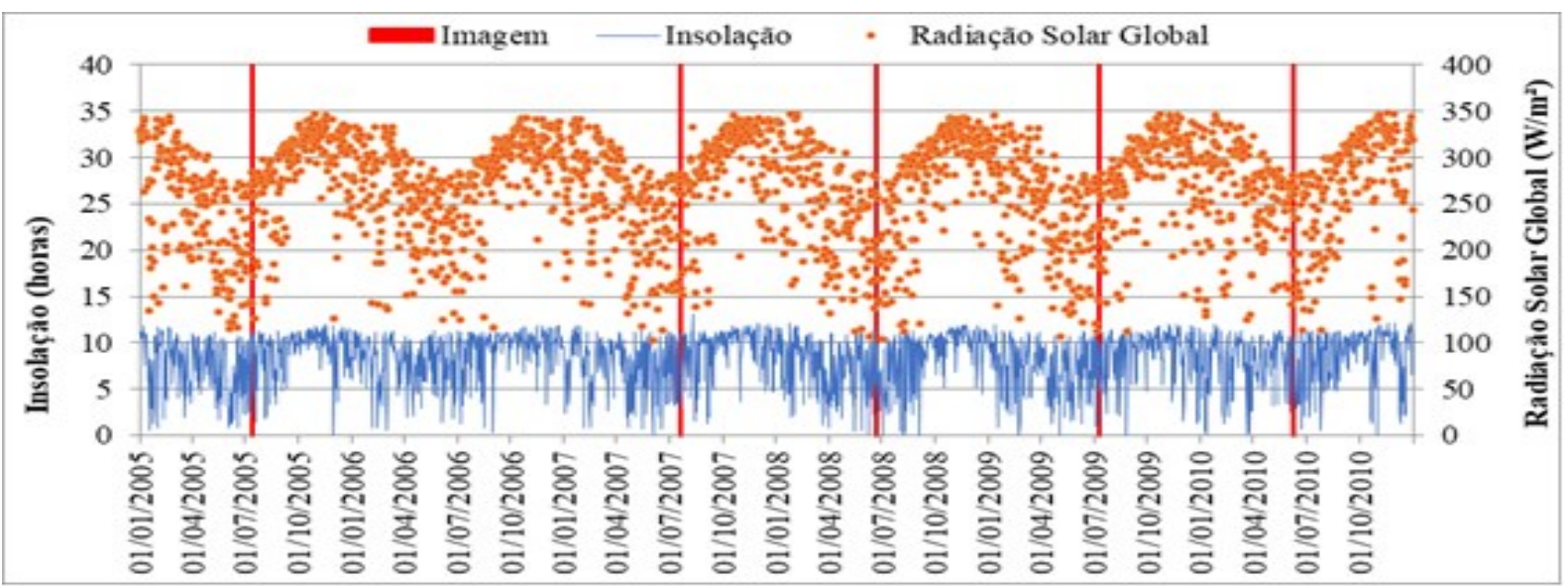

Fonte: Dados da Estação Meteorológica de Cruzeta/RN obtidos através da EMPARN (2012).

O cálculo do Rn foi realizado para cinco imagens do Mapeador Temático Landsat 5, ponto/órbita 215/64, datadas em: 13 de julho de 2005, 19 de julho de 2007, 19 de junho de 2008, 08 de julho de 2009 e 09 de junho de 2010, adquiridas no catálogo de imagens do United States Geological Survey (USGS), em formato geotiff com projeção/datum UTM/SAD-69, e escolhidas de acordo com o percentual de cobertura de nuvens na área de estudo.

Para o cálculo do saldo de radiação $(\mathrm{Rn})$ utilizou-se do processamento das imagens pelo software ERDAS, que gerou os dados necessários para a realização da análise espacial dos componentes do Rn, além utilizar o ArcGis para a produção do layout dos mapas temáticos.

O processamento inicial das imagens consistiu no empilhamento das 7 bandas das imagens Landsat 5-TM, necessitando da reamostragem da banda 6 (termal) para resolução espacial de 30x30m. Após serem registradas, foi realizada a calibração radiométrica, conversão do número digital (ND) de cada pixel em radiância espectral monocromática $\mathrm{L} \lambda \mathrm{i}$ para as bandas reflectivas do Landsat 5-TM (canais 1, 2, 3, 4, 5 e 7) segundo relação proposta por Markham e Barker (1987), apresentada no fluxograma da Figura 4. 
Figura 4: Fluxograma do processamento do saldo de radiação instantâneo à superfície (Rn) pelo SEBAL.

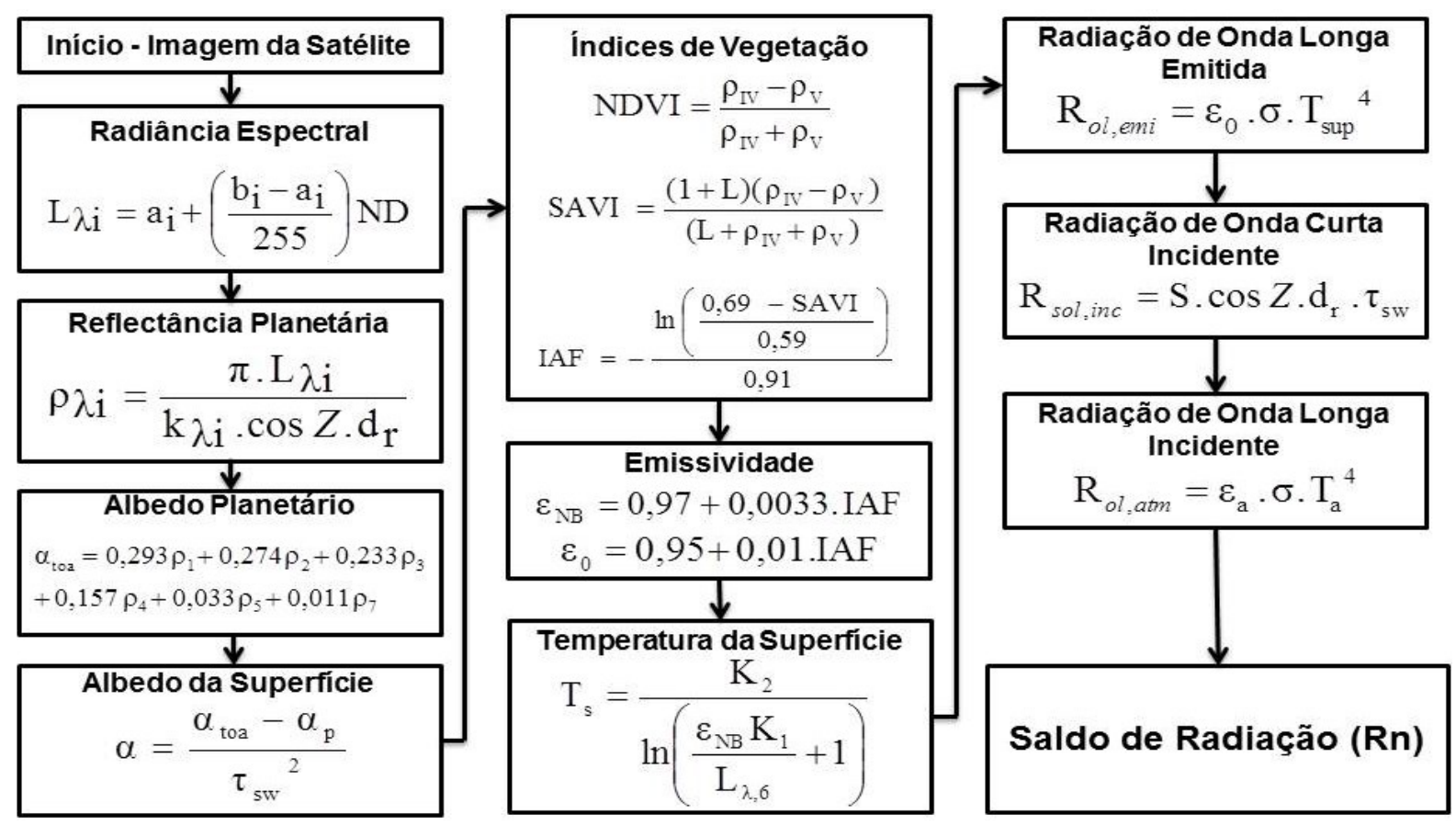

Fonte: Autores (2012).

As radiâncias espectrais mínima (ai) e máxima (bi) $\left(\mathrm{Wm}^{-2} \mathrm{sr}^{-1} \mu \mathrm{m}^{-1}\right)$ foram determinadas por Chander e Markham (2003). Após o cômputo da radiância espectral calculou-se a reflectância planetária para cada banda, definida pela razão entre o fluxo de radiação solar refletida e fluxo de radiação solar incidente.

Em que, é $\rho \lambda i$ a radiância espectral de cada banda $\left(\mathrm{Wm}^{-2} \mathrm{sr}^{-1} \mu \mathrm{m}^{-1}\right)$; A irradiância solar espectral de cada banda no topo da atmosfera $\left(\mathrm{Wm}^{-2} \mu \mathrm{m}^{-1}\right)$ é representada por $\mathrm{k} \lambda \mathrm{i}, \mathrm{Z}$ é o ângulo zenital solar e dr representa o inverso do quadrado da distância Terra-Sol (em unidade astronômica - UA) dado por Iqbal (1983).

Em seguida foram processadas as imagens calibradas para a obtenção das variáveis biofísicas (albedo planetário, albedo superficial, índices de vegetação, emissividade e temperatura de superfície) que antecedem o cálculo das componentes do balanço de radiação.

Sendo que o albedo no topo da atmosfera (planetário) representa o albedo da superfície no domínio da radiação de onda curta $(0,3-3,0 \mu \mathrm{m})$, porém sem correção atmosférica, sendo obtida através de combinação linear das reflectâncias espectrais monocromáticas dos canais reflectivos do Landsat-5 TM. Em que $\alpha$ toa é o albedo planetário, $\rho 1, \rho 2, \rho 3, \rho 4, \rho 5$ e $\rho 7$ são as reflectâncias monocromáticas das bandas $1,2,3,4,5$ e 7 , respectivamente.

Após a obtenção do albedo no topo da atmosfera fez-se o processamento do albedo da superfície $(\alpha)$, ou albedo corrigido para os efeitos atmosféricos, sendo efetuado pela equação exposta na Figura 4, 
onde $\alpha_{\text {toa }}$ é o albedo planetário, $\alpha_{\mathrm{p}}$ é a reflectância da própria atmosfera, que para o modelo foi utilizado o valor de 0,03, com base em Giongo et al. (2010), e $\tau_{s w}$ é a transmissividade atmosférica que foi obtida por (Allen et al., 2002), conforme a equação 2:

$$
\tau_{s w}=0,75+2 \cdot 10^{-5} \cdot z
$$

Sendo $\mathrm{z}$ a altitude de cada pixel (m), que para a aplicação nesse trabalho foi atribuído um valor médio de $350 \mathrm{~m}$, devido a área de interesse não apresentar variações na altitude, obtendo-se $\tau_{\mathrm{sw}}=0,757$.

A obtenção do NDVI, Índice de Vegetação da Diferença Normalizada, sigla em inglês, Normalized Difference Vegetation Index (NDVI) foi efetuada pelo cálculo da razão entre a diferença das refletividades do IV-próximo $(\rho \mathrm{IV})$ e do vermelho $(\rho \mathrm{V})$ e a soma das mesmas reflectâncias, correspondem as bandas 4 e 3 do Landsat -TM 5, respectivamente. Enquanto, o SAVI é um índice de vegetação que visa amenizar os efeitos de "background" do solo, sendo obtido através da equação na Figura 4.

Já o Índice de Área Foliar (IAF) é um indicador da biomassa por unidade de área representada por essa vegetação. O cômputo do IAF, representa a razão entre a área total de todas as folhas contidas em dado pixel e a área do pixel.

Para obtenção da temperatura de superfície (Ts), foi utilizada a equação de Planck invertida sendo necessárias a radiância espectral da banda termal $\left(\mathrm{L}_{\lambda 6}\right)$ e a emissividade no domínio espectral da banda termal $\left(\varepsilon_{\mathrm{NB}}\right)$. Sendo as constantes de calibração da banda termal do Landsat-5 TM, adotadas $\mathrm{K}_{1}=607,76$ $\mathrm{Wm}^{-2} \mathrm{sr}^{-1} \mu \mathrm{m}^{-1}$ e K2 $=607,76 \mathrm{~K}$, conforme Silva et al., 2005.

Após calcular as variáveis biofísicas e de posse de todos os componentes do balanço de radiação, o saldo de radiação instantâneo à superfície foi calculado baseado nos valores dos fluxos de radiação processados anteriormente, conforme a Equação 3.

$$
R n=R_{\text {sol,inc }} \cdot\left(1-\alpha_{\text {sup }}\right)-R_{o l, e m i}+R_{o l, a t m}-\left(1-\varepsilon_{0}\right) \cdot R_{o l, a t m}
$$

Sendo: $R_{\text {sol,inc }}$ é a radiação de onda curta incidente; $\alpha_{\text {sup }}$ é o albedo corrigido de cada pixel; $R_{\text {ol,atm }}$ é a radiação de onda longa emitida pela atmosfera na direção de cada pixel; $\mathrm{R}_{\mathrm{ol}, \mathrm{emit}}$ é a radiação de onda longa emitida por cada pixel e $\varepsilon_{0}$ é a emissividade de cada pixel.

Já o saldo de radiação diário $\left(\mathrm{Rn}_{24 \mathrm{~h}}-\mathrm{Wm}^{-2}\right)$ foi obtido mediante equação 4 proposta por Bruin (1987):

$$
R n_{24 h}=R s .\left(1-\alpha_{\text {sup }}\right)-110 \cdot \tau_{24 h}
$$

Em que Rs ( $\left.\mathrm{W} \mathrm{m}^{-2}\right)$ é a radiação solar diária medida em estação meteorológica na área de estudo e $\tau_{24 \mathrm{~h}}$ é a transmitância atmosférica média diária na superfície $\left(\mathrm{W} \cdot \mathrm{m}^{-2}\right)$.

Visando avaliar a evolução espaço temporal foram analisados os dados obtidos com o auxílio do programa STATISTICA, obtendo os principais parâmetros estatísticos descritivos, como: média, variância, desvio-padrão, coeficiente de variação, valor mínimo e valor máximo. 


\section{RESULTADOS E DISCUSSÃO}

Na Figura 5 apresentam-se os mapas temáticos do Rn instantâneo para as cinco imagens obtidos com o processamento do SEBAL. Ressalta-se que se considerou a ausência de nebulosidade (nuvens) nas imagens selecionadas para o estudo.

O Rn instantâneo mostrou distribuição espacial semelhante em ambos os dias estudados para a água e a vegetação, que apresentaram os maiores valores encontrados, na faixa de 700 a $600 \mathrm{~W} \mathrm{~m}^{-2}$ (água) e de 600 a $500 \mathrm{~W} \mathrm{~m}^{-2}$ (vegetação), enquanto que o solo exposto apresentou os menores valores, de 500 a $350 \mathrm{~W}$ $\mathrm{m}^{-2}$.

Corroborando aos resultados obtidos por Andrade e Corrêa (2014), os quais estimaram o Rn instantâneo à superfície para a cidade de Santarém-PA. Além de apresentar resultados semelhantes aos de Matos et al. (2016) em que computaram no Entorno do Reservatório de Itaparica - PE valores superiores a $650 \mathrm{~W} \cdot \mathrm{m}^{-2}$ para as regiões de leito de rio.

Já Cavalcante et al. (2016), ao calcularem o Rn pelo algoritmo SEBAL na porção do baixo-médio São Francisco, BA, observaram valores para os corpos d'água da ordem de 731,8 a 797,14 W.m². Enquanto Gusmão et al. (2012), determinando o saldo radiativo na Ilha do Bananal, TO, verificou valores de Rn instantâneo acima de $575 \mathrm{~W} \mathrm{~m}^{-2}$ para corpos d'água. 
Figura 5: Mapa temático da distribuição espacial e temporal do Rn instantâneo para o reservatório Dourado e seu entorno (Currais Novos/RN).

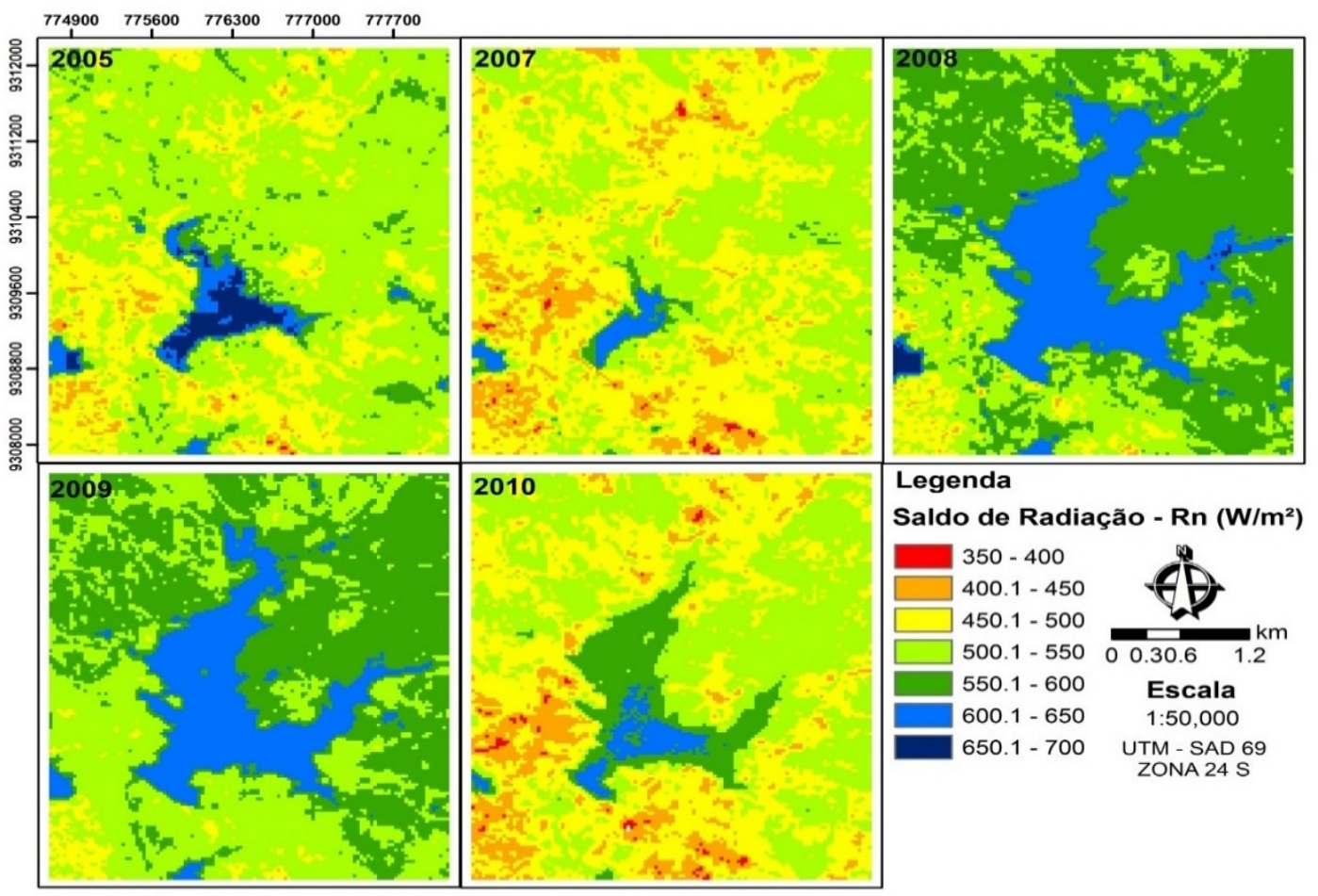

Fonte: Autores (2012).

As áreas de solo exposto se apresentaram em todas as imagens com valores inferiores a $500 \mathrm{~W} . \mathrm{m}^{-2}$. Enquanto Silva et al. (2005) obtiveram, para Juazeiro, BA, e Petrolina, PE, em solo exposto valor de 421,8 W. $\mathrm{m}^{-2}$, enquanto naquela mesma área Di Pace et al. (2008) obtiveram, para solo exposto nos anos de 2000 e 2001, valores de 431,4 e 312,6 $\mathrm{W} \mathrm{m}^{-2}$, respectivamente. Ressalta-se que esses valores dependem de outros fatores, como estoque de umidade do solo, sazonalidade da radiação solar e interferência das chuvas locais (Gusmão et al., 2012).

Segundo Gusmão et al. (2012) deve-se registrar, ainda, que o Rn em corpos d'água depende de vários fatores, tais como: ângulo de incidência dos raios solares, profundidade e turbidez da água, dentre outros.

Constatou-se ainda que a distribuição espacial do $\mathrm{Rn}$ instantâneo esteve condicionado a disponibilidade hídrica da superfície terrestre, tal como pelo estrato de biomassa vegetal presente, ambos limitados nas cenas de 2005, 2007 e 2010 pela sazonalidade climática, decorrente do período de estiagem de precipitações, tal como distribuição temporal irregular de chuvas, fato este averiguado pelas dimensões do espelho d'água do reservatório Dourado, dessa forma provocando modificações na temperatura e no albedo da superfície que tendem a aumentar nestes locais. 
Sendo assim, foi possível comparar as mudanças nos fluxos energéticos de acordo com a mudança na cobertura vegetal da área estudada, reduzindo a quantidade de energia disponível para os processos físicos e biológicos na superfície, de aquecimento do ar (calor sensível), do solo (calor no solo) e fluxo de massa (calor latente).

A distribuição espacial do Rn instantâneo em cada imagem acompanhou um padrão de variação, apresentando baixos valores de Coeficiente de Variação, mostrado na Tabela 1, que destaca os principais valores estatísticos descritivos para os dados extraídos dos pixels das imagens processadas para o $\mathrm{Rn}$ instantâneo.

Tabela 1: Valores estatísticos descritivos aplicados sobre os dados das imagens do Rn instantâneo resultante da aplicação do SEBAL.

\begin{tabular}{ccccccccc}
\hline $\begin{array}{c}\text { Imagem } \\
\text { Ano }\end{array}$ & $\begin{array}{c}\text { Amostra } \\
\text { pixels }\end{array}$ & $\begin{array}{c}\text { Média } \\
2005\end{array}$ & ------ Mediana & Mínimo & Máximo & Variância & DP & $\begin{array}{c}\text { CV } \\
\%\end{array}$ \\
2007 & 16588 & 520,35 & 518,23 & 379,42 & 671,96 & 160,32 & 40,04 & 7,69 \\
2008 & 16588 & 492,16 & 492,90 & 358,54 & 649,19 & 120,98 & 34,78 & 7,07 \\
2009 & 16588 & 568,55 & 564,47 & 416,93 & 665,29 & 167,10 & 40,88 & 7,19 \\
2010 & 16588 & 558,40 & 554,52 & 445,07 & 630,81 & 102,34 & 31,99 & 5,73 \\
\hline
\end{tabular}

Legenda: DP - Desvio Padrão e CV - Coeficiente de Variação.

$$
\text { Fonte: Autores (2012). }
$$

A amplitude dos valores de Rn para as cinco imagens, apresentou valores elevados. Contudo, a aplicação do algoritmo SEBAL é direcionada à superfície, e os valores máximos foram observados para a área do reservatório Dourado, que contribuiu para o aumento, não somente, dessa variável estatística, mas também das outras medidas de dispersão.

Esses valores, segundo Silva et al. (2005), são fortemente modulados pela radiação solar que chega ao solo, e é repartido em energia para aquecimento do ar, aquecimento do solo e para processos evaporativos, que são influenciados pelos fluxos de calor sensível $(\mathrm{H})$, de calor no solo $(\mathrm{G})$ e de calor latente (LE), respectivamente.

Desta forma, corroborando com os resultados obtidos por Amanajás et al. (2013), que ao pesquisarem área de cerrado amazônico, relataram a tendência de maiores valores de $\mathrm{Rn}$ sobre corpos d'água e floresta de transição, enquanto menores valores sobre solo exposto e zona urbana, sendo tal fato explicado pelo efeito combinado do albedo e da temperatura da superfície, pois o primeiro influência o balanço de ondas curtas e o segundo o balanço de ondas longas.

Comparando visualmente as cinco imagens estudadas (Figura 5), verifica-se que as mesmas diferenciam claramente áreas de corpos d'água, vegetação nativa e áreas antropizadas e, de acordo com os 
mapas apresentados, percebe-se que houve uma visível diferença entre os dias estudados, resultado da forte influência da radiação solar global instantânea (Tabela 2).

Considerando os resultados médios em escala temporal, os valores mais elevados do Rn instantâneo foram encontrados nas imagens inseridas em período com maior presença de precipitação, ano com maior índice pluviométrico, ou seja, nas imagens 2008 e 2009.

Essa distribuição foi causada possivelmente pelo desenvolvimento da cobertura vegetal de caatinga, que em períodos chuvosos formam sua biomassa verde devido a maior disponibilidade hídrica no solo, atenuando as condições severas de estresse hídrico. Esse fato reduz o albedo da área em relação ao solo exposto e seco, devido a maior absorção da radiação solar incidente sobre as plantas, o que provoca o incremento do saldo de radiação instantâneo.

Diante do comportamento da vegetação de caatinga frente à variação sazonal da precipitação e a influência sobre os resultados obtidos para as variáveis em estudo, Shusen e Davidson (2007) avaliando alterações devido ao impacto das variações climáticas na pastagem temperada (Grasslands National Park, Canadá), registraram médias maiores do Rn em área de vegetação de caatinga densa (com grande presença de biomassa verde), e justificaram pelo baixo albedo na referida área, tendo-se maior quantidade de radiação de onda curta.

Arraes et al. (2012), avaliando distintos usos em área de vegetação de caatinga densa, irrigação e ação antrópica (áreas degradadas) situados em áreas adjacentes do açude Orós, no sul do Estado do Ceará, também encontraram valores médios em torno de $550 \mathrm{~W} / \mathrm{m}^{2}$, que corroboram aos valores obtidos para as imagens 2008 e 2009 deste trabalho.

Os menores valores de $\mathrm{Rn}$ foram registrados nos períodos mais secos $(2005,2007$ e 2010), de forma geral, houve pouca alteração no saldo de radiação entre as mesmas, concentrando-se os valores entre 332 a $672 \mathrm{~W} \mathrm{~m}^{-2}$.

Visto que o principal fator que interfere na variação dos valores do Rn é a exposição do solo decorrente do comportamento da vegetação de caatinga, que perdem biomassa verde do seu dossel como mecanismo fisiológico e morfológico de defesa a estiagem. Esse comportamento eleva os valores de albedo dessas áreas, que provocam a redução do saldo de radiação disponível à superfície.

Silva et al. (2012), em trabalho comparativo entre vegetação nativa, solo exposto, cultivo irrigado e área sobre reservatório no semiárido paraibano, computaram valores do $\mathrm{Rn}$ em áreas de solo exposto variando entre 470 e $520 \mathrm{~W} / \mathrm{m}^{2}$, apresentando-se inferiores às outras áreas analisadas. Esses resultados apresentaram valores semelhantes aos obtidos neste trabalho, confirmando a excelente aplicabilidade do SEBAL para avaliação temporal dessas variáveis em regiões semiáridas, principalmente para observação do comportamento da vegetação de caatinga nessas condições climáticas. 
Frente aos valores diários do saldo de radiação, é importante ressaltar que estes assumem valores menores quando comparados aos saldos de radiação instantâneos. Isso decorre do balanço diário de radiação considerar horários sem insolação (noite), ou seja, período sem radiação solar incidente durante o dia, quando a radiação disponível à superfície é consumida em processos de evapotranspiração e de aquecimento do solo, o que provoca a redução do valor do Rn em escala diária.

Na Figura 6 observam-se os mapas gerados para o $\mathrm{Rn}_{24 \mathrm{~h}}$ evidenciando que os padrões de distribuição espacial e temporal são idênticos aos observados nos mapas do Rn instantâneo.

Figura 6: Mapa temático da variação espacial e temporal do Rn diário para o reservatório Dourado e seu entorno (Currais Novos/RN).

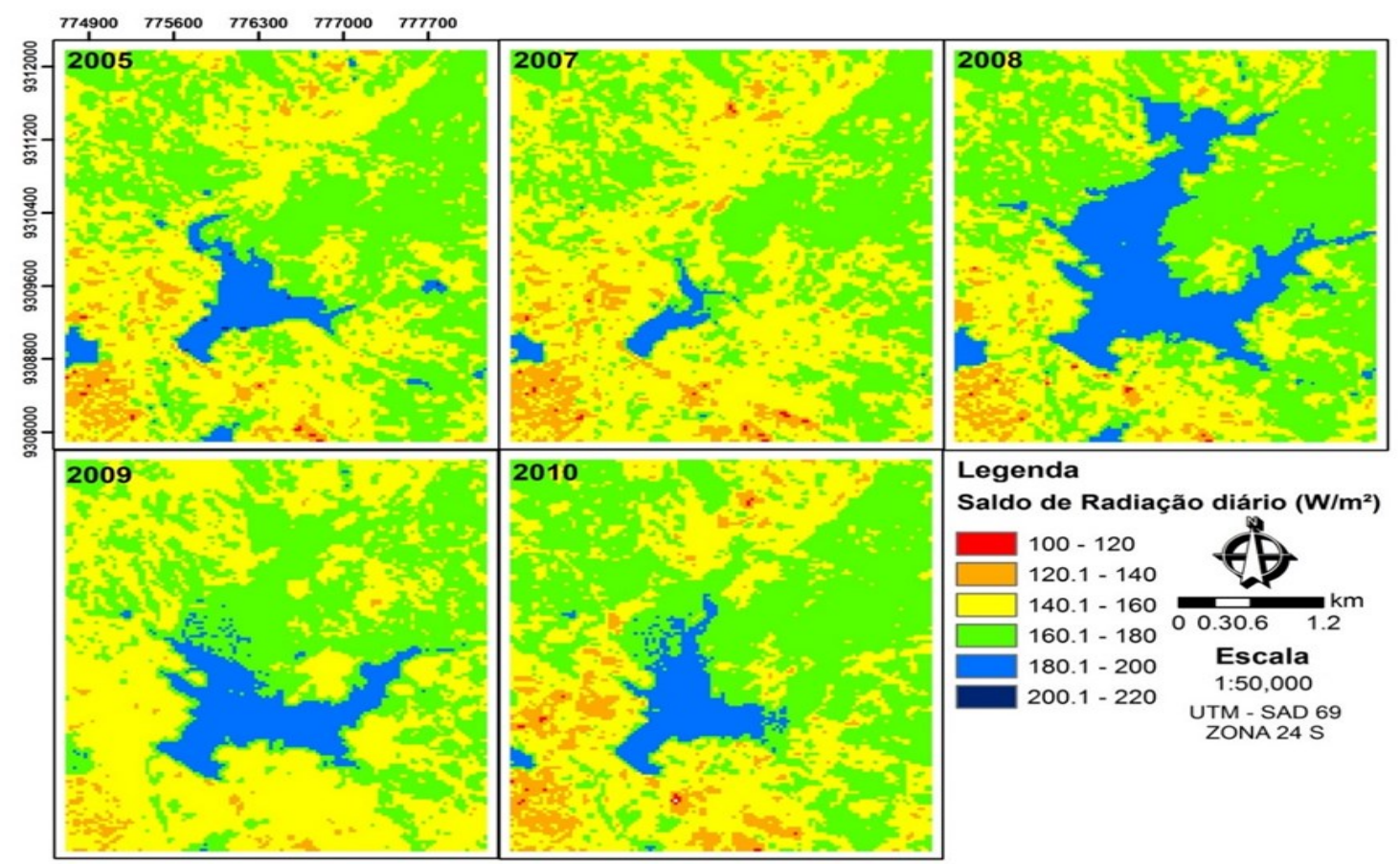

Fonte: Autores (2012).

Analisando-se a variação espacial do $\mathrm{Rn}_{24 \mathrm{~h}}$, percebe-se nos mapas temáticas, que houve uma baixa amplitude, desconsiderando-se os valores mais elevados, que compreendem o reservatório Dourado. Apesar da heterogeneidade que envolve a área de entorno do reservatório, o comportamento da vegetação de caatinga e de solo exposto prevaleceu sobre esses pontos de atividades agropecuárias, devido à pequena abrangência que esses usos do solo possuem no geral. Esse fato pode ser comprovado por valores obtidos por Silva et al. (2012), que encontraram valores de $\mathrm{Rn}_{24 \mathrm{~h}}$ variando de 90 a $200 \mathrm{~W} / \mathrm{m}^{2}$, sendo os menores valores para solos expostos e afloramentos rochosos, enquanto os maiores valores remetem-se as áreas com superfície molhada, com os valores intermediários representando áreas com vegetação nativa (caatinga) densa. 
Na Figura 6 pode ser observado valores de $\mathrm{Rn}_{24 \mathrm{~h}}$ variando de 100 a $220 \mathrm{~W} . \mathrm{m}^{-2}$, sendo os menores valores para solos expostos e áreas antropizadas pela urbanização, com valores inferiores a 160 W.m , seguidos dos valores de 160 a $180 \mathrm{~W} \cdot \mathrm{m}^{-2}$, obtidos de superfícies cobertas por vegetações nativas (caatinga), além das áreas com superfície molhada com valores da ordem de 180 a $220 \mathrm{~W} \cdot \mathrm{m}^{-2}$.

Silva et al. (2011) encontraram valores de $\mathrm{Rn}_{24 \mathrm{~h}}$ entre 173,4 a 196,6 W.m ${ }^{-2}$ e 95,6 a 112,5 W.m ${ }^{-2}$ para o Açude São Gonçalo e solo exposto no estado da Paraíba, respectivamente, em ocasião de maior oferta de radiação solar. Estando de acordo com os resultados obtidos no presente estudo.

A ocorrência dos maiores valores de Rn tenderam a acompanhar as áreas com maiores valores de NDVI e SAVI, exceto quando da presença de água, a qual apresenta baixa refletância em praticamente todo o espectro solar, consequentemente a energia absorvida nesses locais será alta (Pereira et al., 2007), corroborando com os resultados obtidos por Pavão et al. (2016).

Os mapas temáticos gerados através do sensor TM do Landsat 5 mostram clara diferenciação entre as áreas supracitadas (corpo d'água, áreas antropizadas, solo exposto e vegetação nativa).

A Tabela 3 simplifica os valores dos mapas em dados estatísticos descritivos que permitem visualizar a baixa variação espacial dos dados de $\mathrm{Rn}_{24 \mathrm{~h}}$, assim como a distribuição desses valores em relação ao tempo.

Tabela 3: Valores estatísticos descritivos aplicados sobre os dados das imagens do $\mathrm{Rn}_{24 \mathrm{~h}}$ resultante da aplicação do SEBAL.

\begin{tabular}{|c|c|c|c|c|c|c|c|c|}
\hline $\begin{array}{c}\text { Imagem } \\
\text { ano }\end{array}$ & $\begin{array}{c}\text { Amostra } \\
\text { Pixels }\end{array}$ & Média & Mediana & Mínimo & $\begin{array}{l}\text { Máximo } \\
\text { W/m² }\end{array}$ & Variância & DP & $\begin{array}{l}\mathrm{CV} \\
\%\end{array}$ \\
\hline 2005 & 16588 & 160,08 & 160,06 & 107,07 & 201,56 & 154,11 & 12,41 & 7,75 \\
\hline 2007 & 16588 & 156,57 & 157,47 & 110,37 & 192,65 & 113,94 & 10,67 & 6,82 \\
\hline 2008 & 16588 & 164,68 & 163,17 & 111,30 & 196,60 & 171,80 & 13,11 & 7,96 \\
\hline 2009 & 16588 & 161,27 & 159,76 & 123.71 & 184.82 & 105,64 & 10,28 & 6,37 \\
\hline 2010 & 16588 & 159,92 & 161,46 & 98,05 & 189,14 & 149,93 & 12,24 & 7,66 \\
\hline
\end{tabular}

Foi observado que houve variação na amplitude dos Rn, entre as imagens em geral, Tabela 3. Essa característica é comum uma vez que a área de estudo possui considerável heterogeneidade, além de compor um ciclo de 6 anos de estudo, podendo ainda considerar que a fonte de energia solar incidente é determinante para gerir os valores de $\mathrm{Rn}$ anual.

De acordo com o Zwart et al. (2006), valores de Coeficiente de Variação abaixo de 9\% indicam extrema homogeneidade no padrão de distribuição espacial. Portanto, o Rn instantâneo (Tabela 2) e o $\mathrm{Rn}_{24 \mathrm{~h}}$ (Tabela 3) das imagens em estudo apresentam-se em um padrão espacial, podendo concluir que há uma estabilidade na variabilidade dessas duas variáveis para a área avaliada (Giongo et al., 2011). 
De modo geral, pode-se atribuir a diminuição do $\mathrm{Rn}_{24 \mathrm{~h}}$ médio encontrado na cena de 2007, a sazonalidade da radiação solar e do conteúdo de água no solo no momento da passagem do satélite sobre a área em estudo. Enquanto a cena de 2008, apresentou o valor de $\mathrm{Rn}_{24 \mathrm{~h}}$ médio mais elevado, esse comportamento deve-se, em parte, ao solo se encontrar mais úmido em junho de 2008 em função da intensa precipitação verificada (Figura 2).

Observa-se a partir dos valores médios de cada imagem, e também dos mapas temáticos da Figura 6, uma baixa variação do Rn diário em escala temporal. Esse fato também é comprovado pela pequena variação dos valores médios de cada imagem em relação à média geral de todas as imagens, que foi de 160 $\mathrm{W} / \mathrm{m}^{2}$. Esse valor foi aproximado ao encontrado por Silva et al. (2012), que também obtiveram baixa variação sazonal para as imagens estudadas, sendo áreas de solo exposto, reservatório e cultivos irrigados.

Na Figura 7 o gráfico boxplot também permite essa observação diante da baixa variação dos valores medianos, contudo há uma presença significativa de outliers, valores extremos de máxima e de mínima, que são justificados pelos resultados que compreendem o reservatório Dourado e pelas áreas de solo exposto e/ou áreas antropizadas, respectivamente.

Figura 7: Gráfico boxplot para os dados das cinco imagens de $\mathrm{Rn}_{24 \mathrm{~h}}$.

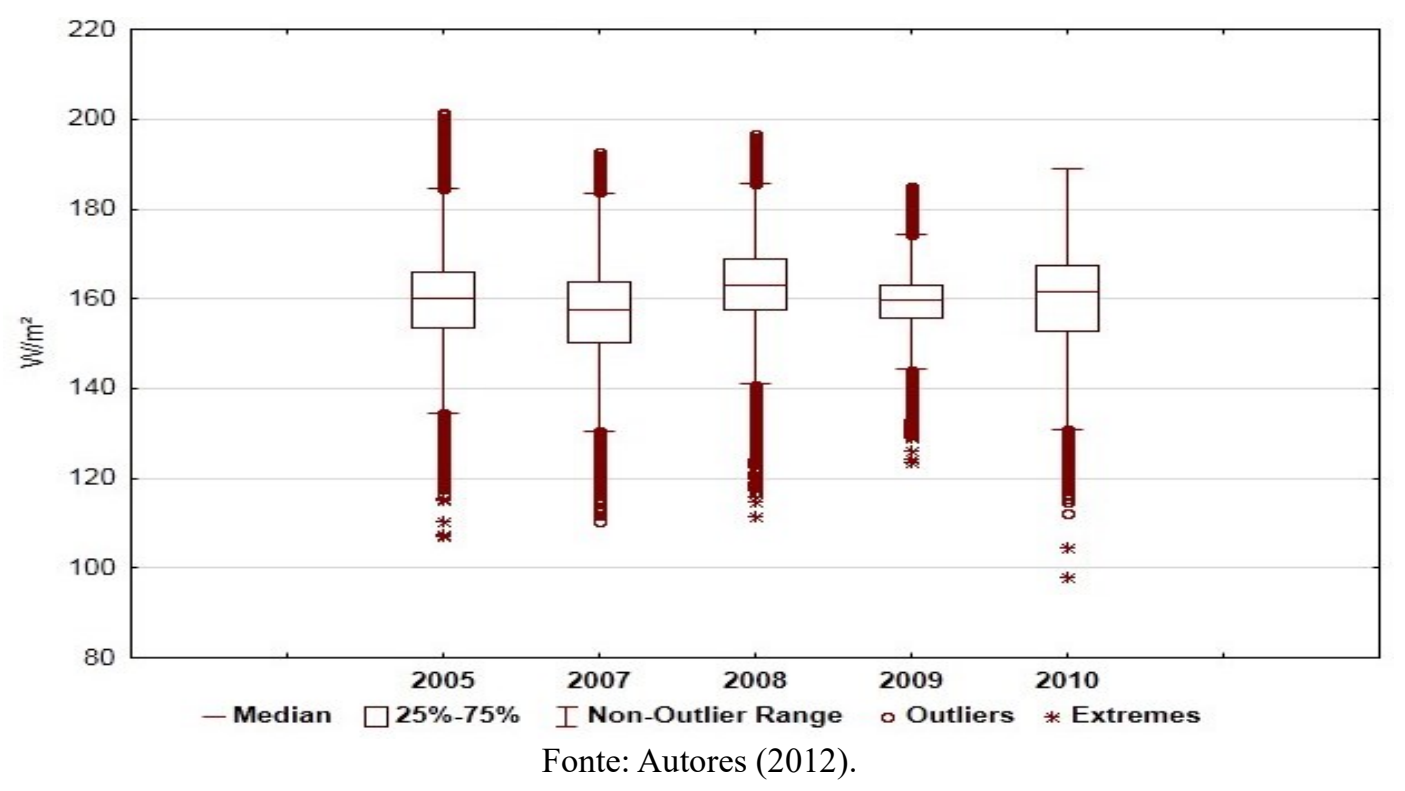

A distribuição dos dados de $\mathrm{Rn}_{24 \mathrm{~h}}$ para as imagens 2005, 2008 e 2009 apresenta-se de forma simétrica, enquanto que para os anos de 2007 e 2010 os valores se distribuem assimetricamente em relação à mediana, concentrado os resultados abaixo da mesma.

Pode-se avaliar, através dos mapas temáticos apresentados, que a dinâmica de uso e ocupação do solo no entorno do reservatório, associada com os usos múltiplos não consultivos do mesmo, influenciam diretamente o clima local, haja vista que um saldo maior de radiação está diretamente associado a um albedo 
pequeno, maior quantidade de água e/ ou maior índice de vegetação e menor Ts, que reúnem condições para proporcionar alto valor do fluxo de calor latente e baixo calor sensível. Em contrapartida, um albedo aumentado com a presença humana (material em suspensão na água podendo causar assoreamento do mesmo, estresse hídrico da planta e a sua própria retirada), em geral reduz o Rn e os índices de vegetação e contribui para aumentar a Ts e o fluxo de calor sensível, resultando em aumento na temperatura do ar.

\section{CONCLUSÕES}

1 - O Rn instantâneo e o $\mathrm{Rn}_{24 h}$ sofreram influência da precipitação em sua variação sazonal em regiões semiáridas, provocada pela disponibilidade de água no solo e pelo desenvolvimento da vegetação de caatinga para essas condições.

2 - A distribuição espacial do $\mathrm{Rn}$ instantâneo e do $\mathrm{Rn}_{24 \mathrm{~h}}$, para as cinco imagens, apresentou-se em um padrão, causado pela pequena dimensão das diversas atividades antrópicas desenvolvidas as margens do reservatório, que sofreram influência do seu entorno, modificando a área de vegetação nativa (caatinga).

3 - O método proposto para estimar o Rn instantâneo superfície, mostrou-se bastante eficaz e consistente, não carecendo de parâmetros de entrada obtidos em superfície e foi capaz de estimar o Rn à superfície, estando os resultados obtidos compatíveis com informações reportadas na literatura e com produtos gerados a partir de imagens orbitais para locais similares à realidade constatada na área de estudo.

4 - Foi possível avaliar, espacialmente, as mudanças ocorridas no Rn e, em consequência, os impactos antrópicos sobre a temperatura do ar em áreas que não possuem informações micrometeorológicas.

\section{REFERÊNCIAS}

ANDRADE, S.C.P.; CORRÊA, J.A.J. Estimativa do saldo de radiação instantâneo à superfície para a cidade de Santarém-PA, através de imagens do Landsat 5-TM. Revista Brasileira de Geografia Física, v. 07, n. 4, p. 653-661, 2014.

ALLEN, R.G.; TASUMI, M.; TREZZA, R. "SEBAL (Surface Energy Balance Algorithms for Land): advanced training and user's manual - Idaho Implementation”, version 1.0, 97 p, 2002.

ALLEN, R.; IRMAK, A.; TREZZA, R.; HENDRICKX, J.M.H.; BASTIAANSSEN, W.; KJAERSGAARD, J. Satellite-based ET estimation in agriculture using SEBAL and METRIC. Hydrological Processes, 25, p. 4011-4027, 2011.

AMANAJÁS, J.C.; BRAGA, C.C.; ALCÂNTARA, C.R.; SOUSA, L.F.; OLIVEIRA, G.B. Estimativa do saldo de radiação à superfície em área de cerrado amazônico utilizando imagem Landsat 5 - TM. In: Anais XVI Simpósio Brasileiro de Sensoriamento Remoto - SBSR, Foz do Iguaçu, PR, Brasil, 2013, 1721 1718. 
ANGSTRÖN, A. Solar e terrestrial radiation. Quarterly Journal, Royal Meteorological Society, 50:121126, 1924.

ARRAES, F.D.D.; ANDRADE, E.M. de; SILVA, B.B. da. Dinâmica do balanço de energia sobre o açude Orós e suas adjacências. Revista Caatinga, 25,119-127, 2012.

BEZERRA, J. M. Estimativa da evapotranspiração real para área de Caatinga utilizando o SEBAL. Tese (Doutorado) Recife, UFRPE, 2013.

BEZERRA, J.M.; MOURA, G.B.A.M.; SILVA, B.B.; LOPES, P.M.O.; SILVA, E.F.F. Parâmetros biofísicos obtidos por sensoriamento remoto em região semiárida do estado do Rio Grande do Norte, Brasil. Revista Brasileira de Engenharia Agrícola e Ambiental, v. 18, n. 1, p. 73-84, 2014.

BRAGA, C.C.; SOARES, F.R.; DANTAS, F.R.C.; BARBIERI, L.F.P. Determinação do albedo e índice de área foliar usando o sensor TM / LANDSAT 5. Anais XIV Simpósio Brasileiro de Sensoriamento Remoto, Natal, Brasil, INPE, p. 935-942, 2009.

BRUIN, H.A.R. de. From Penman to Makkink. In: Hooghart, J. C. (ed.). Proceedings and information: TNO Committee on Hydrological. Gravennhage, The NetheRLands 39, p. 5-31, 1987.

CAVALCANTE, L.B.; INÁCIO, A.L.; BARROS, H.G.; JIMÉNEZ, R.M.N.; COELHO, S.M.S.C. Cálculo do saldo de radiação pelo algoritmo SEBAL na porção do baixo-médio São Francisco, Brasil, utilizando um software de código livre. Revista Brasileira de Cartografia, 68, p. 1515-1529, 2016.

CHANDER, G.; MARKHAM, B. Revised Landsat-5 TM Radiometric Calibration Procedures and Postcalibration Dynamic Ranges. IEEE Transactions on Geoscience and Remote Sensing, 41, p. $2674-$ 2677, 2003.

FIETZ, C. R.; FISCH, G. F. Avaliação de modelos de estimativa do saldo de radiação e do método de Priestley-Taylor para a região de Dourados, MS. Revista Brasileira de Engenharia Agrícola e Ambiental, v. 13, n. 4, p. 449-453, 2009.

GIONGO, P.R.; MOURA, G.B.A.; SILVA, B.B. DA; ROCHA, H.R.; MEDEIROS, S.R.R.; NAZARENO, A.C. Albedo à superfície a partir de imagens Landsat 5 em áreas de cana-de-açúcar e cerrado. Revista Brasileira de Engenharia Agrícola e Ambiental, v. 14, n. 3, p. 279-287, 2010.

GIONGO, P.R., MOURA, G.B.A., SILVA, A.P.N., MEDEIROS, S.R.R. Uso de sensoriamento remoto para estimar o saldo de radiação em áreas de cana-de-açúcar e cerrado. Revista Científica Eletrônica de Agronomia, 18, p. 8-21, 2011.

GUSMÃO, A.C.V.L.; SILVA, B.B.; MONTENEGRO, S.M.G.L.; GALVÍNCIO, J.D. Determinação do saldo radiativo na Ilha do Bananal, TO, com imagens orbitais. Revista Brasileira de Engenharia Agrícola e Ambiental, v. 16, n. 10, p. 1107-1114, 2012.

IQBAL, M. “An Introduction to Solar Radiation”. New York: Academic Press. 212p, 1983.

MARKHAM, B.L.; BARKER, J.B. Thematic mapper band pass solar exoatmospherical irradiances. International Journal of Remote Sensing, 8, p. 517-523, 1987.

MATOS, R.C.M.; CANDEIAS, A.L.B.; AZEVEDO, J. R. G. Estimativas do Saldo de Radiação Instantâneo no Entorno do Reservatório de Itaparica - PE com uso de Imagens Orbitais. Revista Brasileira de Cartografia, v. 68, n. 3, p. 641-654, 2016.

MOREIRA, E.B.M.; NÓBREGA, R.S.; SILVA, B.B. Estimativa do Saldo de Radiação Instantâneo na Cidade do Recife, Através de Imagens do Satélite Landsat $5 \mathrm{Tm}$. Revista Brasileira de Geografia Física, v. 04, n. 03, p. 589-601, 2011. 
PAVÃO, V.M.; QUERINO, C.A.S.; BENEDITTI, C.A.; PAVÃO, L.L.; QUERINO, J.K.A.S.; MACHADO, N.G.; BIUDES, M.S. Variação espacial e temporal do saldo de radiação superficial em uma área do sul do Amazonas, Brasil. R. Ra'e Ga, 37, p. 333-352, 2016.

SÁ, P.C.C.; ESPÍNOLA SOBRINHO, J.; SILVA, S.T.A.; FERREIRA, R.C.; MOURA, M.S.B. Estimativa do saldo de radiação em cultivo irrigado de cana-de-açúcar utilizando dados de sensoriamento remoto orbital. Revista Brasileira de Geografia Física, 09, p. 2164-2178, 2016.

SHUSEN, W.; DAVIDSON, A. Impact of climate variations on surface albedo of a temperate grassland. Agricultural and Forest Meteorology, 142, p. 133-142, 2007.

SILVA, B.B. da; LOPES, G.M.; AZEVEDO, P.V. de. Balanço de radiação em áreas irrigadas utilizando imagens Landsat 5-TM. Revista Brasileira de Meteorologia, 20, p. 243-252, 2005.

SILVA, B.B. da; BRAGA, A.C.; BRAGA, C.C. Balanço de radiação no perímetro irrigado São GonçaloPB mediante imagens orbitais. Revista Caatinga, 24, p. 145-152, 2011.

TEIXEIRA, A.H.C.; BASTIAANSSEN, W.G.M.; AHMAD, N.D.; MOURA, M.S.B.; BOS, M.G. Analysis of energy fluxes and vegetation-atmosphere parameters in irrigated and natural ecosystems of semi-arid Brazil. Journal of Hydrology, 362, p. 110-127, 2008.

TEIXEIRA, A.H.C.; BASTIAANSSEN, W.G.M. AHMAD, M.D.; BOS, M.G. Reviewing SEBAL input parameters for assessing evapotranspiration and water productivity for the LowMiddle São Francisco River basin, Brazil Part B: Application to the large scale. Agricultual and Forest Meteorology, 149, p. 477-490, 2009.

TEIXEIRA, A.H.C.; BASSOI, L.H.; LOPES, H.L.; HERNANDEZ, F.B.T. Análises dos componentes dos balanços de radiação e de água por sensoriamento remote em videiras para mesa no município de Petrolina-PE, Brasil. In: Simpósio Brasileiro De Sensoriamento Remoto, 15., 2011, Curitiba. Anais... Curitiba: INPE, p. 71-77, 2011.

VILLELA, S.M.; MATTOS, A. Hidrologia aplicada. São Paulo, McGraw-Hill do Brasil, 245p. 1975.

ZWART, S.J.; BASTIAANSSEN, W.G.M.; GARATUZA-PAYAN, J.; WATTS, C.J. SEBAL for detecting spatial variation of water productivity for wheat in the Yaqui Valley, Mexico. Earth Observation for Vegetation Monitoring and Water Management, American Institute of Physics, p. 154-161, 2006. 